\title{
COMMENT
}

\section{Economies of scale}

\author{
Gregory A Petsko*
}

If you're a young scientist and you want to start the day off with a pick-me-downer, you'll find it in the 7 March 2012 online edition of The Atlantic [1]. You can't miss it: it has the eye-catching headline 'Do we really need more scientists?' It's an opinion piece by organic chemist Derek Lowe, who works in the pharmaceutical industry and who appears to think we do. He starts by pointing out that smart people who want to get rich will probably choose Wall Street over the sciences, and then states, 'It takes a certain personality type to really get into this stuff'. The type, he explains, likes figuring things out and making complicated things work, and is driven by curiosity, so clearly the scientific life is not for everyone. But then he gets down to the real problem with the science labor market: a dearth of jobs. 'A lot of people with physics and chemistry degrees are having trouble finding work', he asserts, 'and in my own degree field (synthetic organic chemistry), it's been a real feat not having your job evaporate out from under you. In many cases, these jobs are going off to lower-labor-cost areas like China or India, but some of them are just disappearing outright', concluding with the advice, 'Be light on your feet...learn how to learn, and don't assume that you've ever won some sort of lasting job security, because lasting job security isn't something that the world's economy is built to deliver these days'

One man's opinion? Well, yes, but I hear it echoed in university cafeterias and government-sponsored workshops, and in the corridors where the powerful people who shape science policy (and set its funding levels) talk to each other. Nature Medicine even highlighted it: 'Survey says: too many $\mathrm{PhDs}$ ' was its eye-catching headline [2]. It's the first public release of information from a working group created last year by the US National Institutes of Health (NIH) to study strategies for maintaining a sustainable pool of researchers. They surveyed 219 scientists, research administrators and research trainees - a number whose adequacy in terms of size and randomness I would question - and found that a dearth

${ }^{*}$ Correspondence: Gregory A Petsko petsko@brandeis.edu Rosenstiel Basic Medical Sciences Research Center, Brandeis University, Waltham, MA 02454-9110, USA of jobs was their number one concern. And so, as Rebecca Hersher, who wrote the feature, puts it, 'rather than relying on increased funding for the $\mathrm{NIH}$, the working group is considering suggestions that include reducing the number of training grants for $\mathrm{PhD}$ students and postdoctoral fellows, creating more programs for biomedical master's degrees rather than full-blown doctorates and providing preparation for jobs outside tenure-track academic research, according to the panel's co-chair Sally Rockey, who is also the NIH's deputy director for extramural research'.

No market-based enterprise is totally immune from the law of supply and demand. When supply of something exceeds the demand, the value of that good (or service, or type of worker) goes down. Put another way, if you produce a great deal of just about anything, the demand for it will probably not keep up with the supply; to bring them into balance you have to produce less, unless you find a way to inflate the demand by, typically, lowering the price. However, not everything operates as a pure market-based enterprise. Science doesn't - in particular, the science labor market. Postdoctoral scientists and graduate trainees are in theory free to sell their services to the highest bidder, and if there were a glut of such employees you would ordinarily expect their wages to fall, but in fact the salaries of scientific trainees are confined within close limits, and those limits are set by the policies of the NIH, chiefly, and not by marketplace demand.

Such wage control means that the only constraint on demand is the number of fellowships and grants that NIH awards, and when the NIH budget increases, as it usually does, the supply of scientific labor at the entry level is free to rise with it. Coupled with that is ever-growing pressure on heads of laboratories to produce more papers and patents, usually best achieved by having their laboratories get bigger. But while the entry-level labor market may not be a free one, the availability of posttraining jobs in the life sciences is to a large extent constrained by market forces, leading to the peculiar situation we find ourselves in: there is a growing demand for people to be trained as scientists, while the demand for trained scientists is steady or falling.

In other words, I argue that an imbalance of supply and demand, if one exists (and I concede that most people certainly think it does), is a symptom, not a cause, of what 
ails science today. I believe there are a number of causes, including an overemphasis on big science projects at the expense of individual investigator-initiated research (I call this The Manhattan Project Syndrome) and too many so-called 'soft-money' positions, where the scientist is responsible for raising the funds for his or her salary by obtaining research grants. There has been a lot of talk about these problems of late, but not a lot of agreement about what to do about them. I think the most important cause of our apparent labor glut is something I haven't heard talked about. It is, simply, that the size of the scientific enterprise has outstripped the structure we have for it.

If you read only one book about either science or economics this spring, read How Economics Shapes Science by Paula Stephan [3]. An economist at Georgia State University and a member of that NIH working group, Paula (we are on a first-name basis) has produced what I think may be the most important book on the state of science since the legendary Big Science, Little Science by Derek J de Solla Price, published in 1963 [4]. Paula analyzes the scientific enterprise in terms of its incentives and costs, and tackles such subjects as the current funding crisis with clarity and sense. She concludes that the main incentives for scientists are not directly financial, but rather prestige and priority. But these incentives came into being when there were far fewer scientists and considerably more research dollars available. Among her arguments is that the combination of expanding universities and stagnant budgets has made funders and scientists more risk averse, and stunted the development of young investigators.

Paula pays particular attention to the period when the NIH budget doubled (1998 to 2002). This vast influx of funding had many unanticipated consequences, among which were: success rates for individual investigatorinitiated grant applications didn't rise, but fell significantly by 2009; universities used the funding to justify a building binge, partly to lure star faculty from other institutions and partly to create capacity for the anticipated increase in grants; grants grew in size, absorbing more costs, including those of more cheap labor (that is, graduate student and postdoc salaries).

Paula notes that the short-term nature of the doubling, combined with the long-term nature of the resulting grant commitments, created a dearth of money in subsequent years, as funding fell in inflation-adjusted dollars yet previous commitments remained. She also offers persuasive evidence that the NIH took money away from the individual grant pool during the expansion to pursue other, larger initiatives.

While no-one would argue that bigger is always better, many individuals - and organizations, NIH included operate as though they think it is. Growth for its own sake is sometimes justified by the doctrine of economies of scale: that is, an enterprise can lower its operating costs by expanding; or the average cost of producing something falls as the volume produced increases. Often that is true, but not always; misunderstanding this doctrine has led to many problems. There is no evidence, for example, that: big science produces more breakthroughs per dollar than little science, at least not overall (my suspicion is that it produces fewer); expanding the total size of the scientific labor pool shortens the time between breakthroughs and their applications - that lag is as often set by cultural and political forces as it is by the availability of human resources (there is, however, a lot of evidence that specific problems, and specific diseases, can be conquered when they are allocated more money).

For the sake of discussion, assume that science has gotten too big for the structures that evolved when it was much smaller, and we are training more scientists than the market can absorb. (And neglect, for the moment, the possibility that the real problem is the expectation that such trainees must become practicing scientists for the training to be considered successful - a possibility I largely subscribe to, and, if true, suggests that we should adjust expectations before tinkering with numbers.) On that assumption, what would be the most sensible response?

In a recent interview in Inside Higher Ed, Paula had this to say about the labor situation [5]:

The evidence is overwhelming that in certain fields especially in the biomedical sciences - we produce more PhDs than there are research or teaching jobs. This imbalance is caused by the fact that principal investigators staff their labs with postdocs and graduate students, not permanent staff scientists. Faculty like the model: graduate students and postdocs have new, fresh ideas; they are also inexpensive and they are temporary. But unless the number of new jobs grows quickly enough to absorb the newly trained, (which it hasn't for many years), this system of staffing produces many more PhDs than the job market can absorb. That's why I call it a pyramid scheme.

What can we do about it? First, graduate programs need to be required to provide potential students with job outcome data so that students enter into the arrangement with their eyes wide open, rather than find out three to four years down the road that research and teaching jobs are few and far between. Second, we need to bite the bullet and substitute permanent staff scientists for at least some of the postdocs and graduate students. They're more expensive, so it won't be a one-to-one swap, but, being permanent, they will not contribute to an ever-expanding supply of graduates who can't find the types of jobs they trained for. Finally, because much of the demand for graduate students and postdocs is driven by PIs in 
soft-money positions, we could curtail the demand for graduate students and postdocs by limiting the amount of salary that can be written off on grants.

When you start to think about the problem in these terms, other ideas come rapidly. Here is another: instead of limiting the amount of salary that can be written off on grants, limit grant size, or total amount of grant dollars an investigator can have at any given time.

While such direct structural intervention would probably lead to an adjustment in labor supply, it would require constant tinkering as the situation evolves. I am uncomfortable with giving federal agencies more license to direct the scientific enterprise. I do like Paula's first two suggestions very much, but the third not so much. I have, I think, a better idea.

Let's re-establish a proper labor market. One way would be to remove any restrictions on postdoctoral and graduate student salaries, at either the high end or the low end. If we really are training too many life scientists, salaries will fall, and fewer young people will choose that path. Eventually, supply will catch up with demand and wages should increase. While that might be ideal from a strict economic perspective, I think the imbalance of power between employer and employee is too great in academic science, and there would be too many opportunities for outright exploitation in this system. There is another way, which I think makes a lot of sense: double the $\mathrm{NIH}$-set salary scale for graduate students and postdocs.

That seems counterintuitive: wouldn't raising salaries just encourage more people to go into science? In theory, yes, but remember that the present system has a freefloating supply but an artificially controlled demand. Demand is set by the amount of money available to pay graduate students and postdocs. If this remains roughly flat, as it probably will for the next few years at least, the way to reduce demand is to make each trainee much more expensive. Then trainee numbers will have to fall. If this salary increase is phased in over 4 to 5 -years there would be time for labs to downsize by not replacing everyone leaving in the ordinary turnover.

We would then be finally paying these dedicated, hardworking, skilled laborers something closer to their worth - and what they would earn doing similar work in the private sector. Of course, I can hear people scream now that this will ruin science and cripple our ability to compete with countries like China and India, but I'm not persuaded that it will. There is no evidence that bigger labs do more innovative work, which is what we're really looking for, and if trainees cost more wouldn't it make sense to keep the best trainees? I think my solution would largely weed out the bottom end of the labor market, at least eventually, and the effect on productivity should not be severe. Besides, with fewer people to supervise, senior scientists might do an even better job training them.

Wages are hard to decrease once they've gone up (economists call this 'downward stickiness'), so if my suggestion has more of a negative effect on the competitiveness of US science than I think, the government will simply have to increase the funds available for scientific research. And that argument - we need more support because of an acute and easily demonstrable labor shortage - might be one that even our current politicians would understand. By restricting the supply, we might induce some much-needed demand. This is just one fascinating conclusion I am pondering because of Paula's remarkable book. I'll explore another, our riskaverse culture in the life sciences, next month.

Published: 30 April 2012

\section{References}

1. Lowe D: Do we really need more scientists? The Atlantic 7 March 2012. [http://www.theatlantic.com/business/archive/2012/03/ do-we-really-need-more-scientists/254109/]

2. Hersher R: Survey says: too many PhDs. Nat Med 2012, 18:329.

3. Stephan P: How Economics Shapes Science. Cambridge, MA: Harvard University Press; 2012.

4. de Solla Price DJ: Big Science, Little Science. New York: Columbia University Press; 1963.

5. Golden S: 'How Economics Shapes Science'. Inside Higher Ed 9 March 2012. [http://www.insidehighered.com/news/2012/03/09/

interview-author-book-economics-scientific-research]

doi:10.1186/gb-2012-13-4-154

Cite this article as: Petsko GA: Economies of scale. Genome Biology 2012. 13:154. 